\title{
Application of Big Data in Higher Education
}

\author{
Liang-qiu Meng ${ }^{1}$ \\ ${ }^{1}$ School of Marxism \\ Wuhan University of Technology \\ Wuhan, P.R.China, 430070 \\ E-mail: liangqiumeng@163.com
}

\author{
Liang-qiu Meng ${ }^{2}$ \\ ${ }^{2}$ Pre-undergraduate Education School \\ Guangxi University of Nationalities \\ Nanning, P.R.China,530006 \\ E-mail: liangqiumeng@163.com
}

\begin{abstract}
There is a trend that, almost everyone, ranging from government departments to companies to Scholars, is either experiencing or anticipating unprecedented growth in the amount of data available in their world, as well as new opportunities and great value. In particular, this paper will discuss big data Definition, big data feature, and finally its application in higher education.
\end{abstract}

\section{Keywords- big data; higher education}

\section{INTRODUCTION}

With the rapid development and innovation of information technology, our collection of digital data has started to grow rapidly. Nowadays, there are tremendous amount of data generated everyday in the sectors of manufacturing, business and our lives. Since 2009, people have been more and more interested in Big Data. By this year, big data has generated enormous force for change in all walks of life.

What is big data? Definition of big data has not yet to be determined. Different scholars have different views.

As authorities on Big data, Viktor Mayer and Kenneth Cukier gave the following definition in their writing Big Data: A Revolution that Will Transform How We Live, Work and Think: "According to the large quantities of data analysis to get great value products and services Or deeper insights in an unprecedented way."[1]"Big data is not only a technology but also a value and methodology"[2]

Tu Zipei pointed out in his writing Big Data, "Big Data means those big scale data which goes beyond the traditional rule and which is hard to be captured by common software tools." It is usually measured by "the ether". We call it "big" is not only because of its huge capacity but also because of its greater significance in discovering new knowledge and creating new value through exchange, integration and analysis of massive data so that we could get "big knowledge", "big technology", "big profit" and "big development". [3]American Internet data center defined Big data as a new kind of technology architecture which obtains value from large quantities of data by high-speed capture, detection and analysis. [4]

Wikipedia definition of big data is straightforward. Big Data usually includes data sets with sizes beyond the ability of commonly used software tools to capture, curate, manage, and process the data within a tolerable elapsed time. Big data can also be defined as "Big data is a large volume unstructured data which can not be handled by standard database management systems like DBMS, RDBMS or ORDBMS". [5]

Impel Big data research and Development Action
Plan in Shanghai has been more comprehensively generalized. Big data includes three connotations: firstly, the great amount of data, diversity of sources and various types of data sets; secondly, new-style data processing and analysis techniques; thirdly, with an analysis creates value. [6]

\section{BIG DATA FEATURE}

Big data has the following features. Firstly, large amounts of data volume; secondly, a wide range of data variety; thirdly, good real-time and high velocity; finally, extract has a high commercial value by analyzing the big data. There is $4 \mathrm{~V}$ of the Big Data(see figure 1). [7]

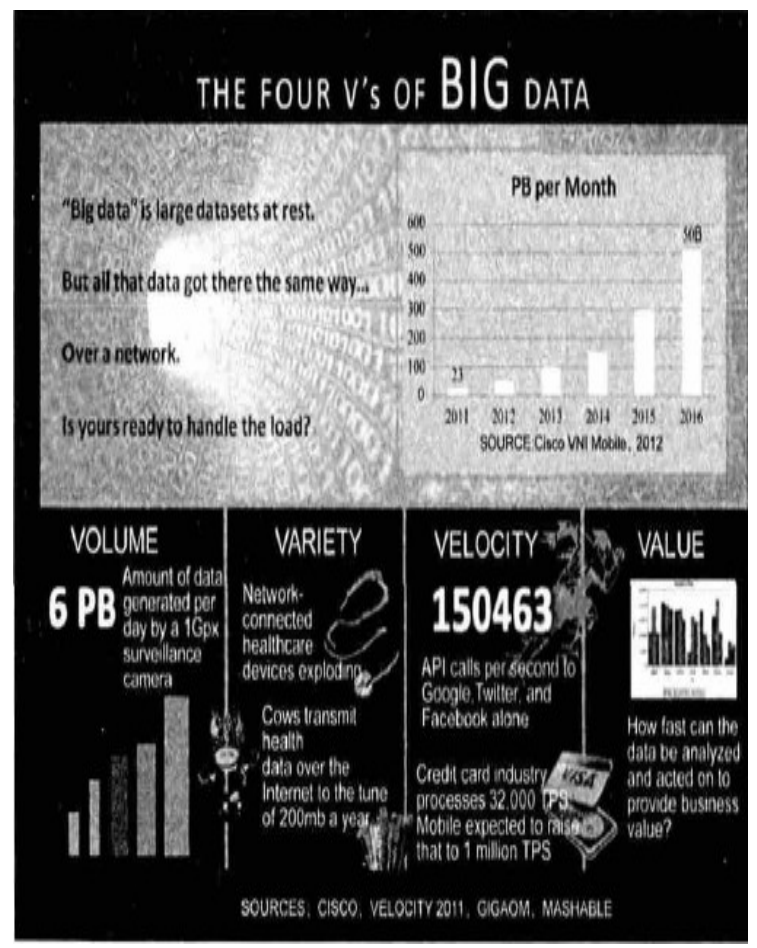

Figure 1. The four V's of BIG data

\section{APPLICATION OF BIG DATA IN HIGHER EDUCATION}

There are many universities in China. In the university, students, courses, scores, books, internet, forum, micro-blog and cards for dining produce a large number of data, and so do the basic information of teachers, the courseware, video, distance teaching courses. Besides, there is information of the equipments, computer rooms and books, etc. Therefore, more often than not, the information system of colleges is very large. After years 
of operation, data that have been accumulated is the big data of university information system. Big data in colleges and universities has a very high value for teaching and researching. It can change teaching and learning mode in the field of education. Big data can also helps with teaching management, scientific computing of massive data, the recruitment campaign and degree management work, etc. In the era of which the information is very precious, teachers and students in the university will benefit from the technology of big data. concern and attention on the ideological and political theory courses in multimedia research teaching applications have greatly increased to a certain extent, we can predict the heat of the field research in next few years would not be a recession.

\section{A. Forecasting}

The core of big data is forecast, which applies mathematical algorithm to predict the likelihood of things happening. This technology can also be used to predict the enrollment, employment, students' demand and the future development of colleges and universities.

\section{B. Providing a new platform for education}

Since 2011, online education has been sweeping American education. A new type of intelligent learning platform is becoming the focus of innovation and investment in high-tech field, many companies have achieved preliminary success. For instance, the famous online education company courses has reached an agreement with more than 30 universities worldwide such as Princeton, Berkeley, Duke, Hong Kong Institute of Technology, it provides courses for free through these platforms.

\section{Developing a new teaching mode}

In the era of big data, the way for learners to acquire knowledge is no longer the classroom, online study is becoming a major way for learning. On the Internet, learners have access to the world's best courses which are better than the courses that are offered by any single university.

\section{Promoting the exchange of research and innovation}

Mainly, big data influences scientific research on higher education in two aspects: one can refer to books and materials more conveniently and more quickly. Rising information of library enhances information service based on Internet search and query be gradually absorbed and practiced by more libraries, which makes efficient $\backslash$ "one-stop $\backslash$ " access possible. Another one is that it provides means of communication between research institutions or experts and scholars in higher education, which is more timely than directly using of books and materials with two-way communication of words, pictures(graphics), sounds and other multimedia at the same time, thus makes effective sharing of vast data possible. Big data era has changed greatly. It is possible to launch research collaboration global, interdisciplinary and on a large scale, share resources and collaborative work across obstacles temporally and spatially. This will change ways and modes for scientists engaging in scientific research, and help them promote their exchanges and cooperation greatly.

On April 10, 2012, Technology office of the Ministry of Education of Federal Government, issued " improve teaching and learning through mining and analyzing of educational data : introduction to problem (hereinafter referred to as" introduction "), pointed out that two specific areas in education will use big data: education data mining and learning analysis. Education data mining analyses data collected in the process of teaching and learning by statistics, machine learning and data mining technology to inspect on study theories and guide education practice. Learning analysis analyses data collected in the process of education management and service by information science, sociology, psychology, statistics, machine learning and data mining technology to directly influence the education practice with its applying program. [8]

\section{CONCLUSION}

More and more rapidly, our era will be changed by big data, including our way of life. Next decade will be the big data era of technology under the guidance of wisdom. This study introduces the definition and characteristics of big data, and its four aspects of the impact of higher education. In summary, research on big data is still at a very preliminary stage today, there are many fundamental problems to be solved. For example, in the university, what is the purpose of the analysis of big data? Whether or not the hardware can meet the need of the analysis of big data ? Whether the technical level of the staff is qualified? There are still lots of difficulties that need to be conquered. We hope this study can provide some reference to big data research fellow scholars.

\section{REFERENCES}

[1]Viktor Mayer-Schönberger, Kenneth Cukier. BIG DATA:A REVOLUTION THAT WILL TRANSFORM HOW WE LIVE, WORK, AND THINK[M].HANGZHOU: ZHEJIANG PEOPLE'S PUBLISHING HOUSE,2013,pp 4 .

[2]Find the key to the future[EB/OL]People's Daily,http://www.people.com.cn/24hour/n/2013/0201/c25408-203 95497.html 2013-02-01.

[3]TU ZIPEI. Big data: Data revolution is coming[M].NANNING: Guangxi Normal University press,2012,pp57.

[4]John Gantz \& David Reinsel. Extracting Value from Chaos[EB/OL].http://www.emc.com/collateral/analyst-reports/idcextracting-value-from-chaos-ar.pdf.

[5]BigData[EB/OL].[2014-5-26].http://en.wikipedia.org/wiki/Big data

[6]http://www.stcsm.gov.cn/gk/ghjh/333008.htm.[EB/OL].[2013-8-7].

[7]]Beyer M A, Laney D. The importance of 'Big Data:' : a definition[M]. Stamford: Gartner, 2012,pp2-5.

[8]Bienkowski M, Feng M, Means B. Enhancing teaching and learning through educational data mining and learning analytics: an issue brief. Washington, D.C. Office of Educational Technology, U. S. Department of Education. 2012,pp9 